mould, very conmon in brown and barley bread \&c.; the conidia are colourless, varying from $1 \mathrm{~m}$. to $2.5 \mathrm{~m}$. in diameter, and, whatis especially noteworthy, thriving best at from $37^{\circ} \mathrm{C}$. to $40^{\circ} \mathrm{C}$., just the heat they meet with in the human body. According to Siebenmann these spores are very widely diffused, and it is quite conceivable that under favourable conditions of heat and moisture they might increase and multiply to an enormous extent, and be extensively disseminated by air currents over vast tracts of country. All evidence during the recent epidemic seems to point to an atmosphere impregnated with pathogenic germs, and it is not a little significant that the period of greatest influenza intensity was marked by comparatively mild, moist, and "muggy" weather. The suddenness of the invasion of influenza, the large numbers simultaneously attacked, the extreme rapidity with which it spreads, and the apparent caprice of its course, all point to an air-borne contagium. In suggesting this theory as to the etiology of influenza, I do not, I need hardly say, wish to assert dogmatically that the spores of the aspergillus fumigatus are absolutely the cause of this obscure disease, but merely that it is more than possible that they or some allied fungus or spore may originate it, and to suggest to those who possess the requisite skill and apparatus a line of research which, I believe, may help to solve this difficult question.-I am, Sirs, yours truly,

Folkestone, Oct., 1891. Chas. Egerton Fitzgerald, M D.

\section{"NEW GUNSHOT WOUNDS COMPARED WITH OLD."}

To the Editors of THE LANCET.

SIRs,-Under the above heading your Berlin correspon. dent, in your issue of Oct. 3lst, p. 1019, draws attention to Thurnwald's statement that by the new bullets "the soft parts are less bruised, and the bones less shattered." In the "Surgical Report of the Belfast Riots," as published by me," referring to the changed character of the bullet wounds of the day, is the following: "I think the altered shape and greater velocity of the modern rifle bullet has much to do with the result. To me it appears less of a crushing and more of a cutting missile, and a study of the records of military surgery from the time of Hunter, Bell, Larry, Guthrie, Hannen, Longmore, and the surgery of the American civil war, will show that, in proportion to the increase in velocity of rifle bullets so did the sloughing from gunshot wounds diminish." The fact that the slow velocity is the principal cause of the bruising is first, I think, suggested by Richard Wiseman in the introduction to his treatise on "Gunshot Wounds," in which the following passage occurs: "What I have said of gunshot happeneth at sea frequently by a splinter, which, though it may have lost its force to make a wound, yet it sometimes bruiseth the skin to the flesh so forcibly as to extinguish the natural heat, and to make it black" (see ed. 1686).

I am, Sirs, yours truly,

Dublin, Oct. 31st, $1891 . \quad$ GEORGE FoY, F.R.C.S.I.

\section{THE BELFAST ROYAL HOSPITAL.}

\section{To the Editors of THE LANCET.}

SIRS,-I have seen a paragraph in THE LANCET headed "Belfast Royal Hospital," bearing upon a recent inquest in that institution and the sanitary condition of the hospital. Were it not that $I \mathrm{am}$ in the midst of scholarship examina tion papers in connexion with Queen's College, Belfast, and that other matters of a grave character press upon me jus now, I should have been disposed to furnish you with a full and complete statement of the case as it came before me at the inquest. In the meantime, may I request you will be so good as to insert in an early issue of your valued periodical, the report of the medical and surgical staff of the Belfast Royal Hospital, with my short statement in reply, as they appear in the Belfast papers. I herewith forward them for your nse. The short statement which appeared was all the length I considered ib necessary or right to go in the daily papers; but as the subject has been entered upon in THE LANCET, I hope you will see the propricty of giving publicity to the "report," and also to my brief reply. The subject has been much commented upon here in professional circles, and it has naturally excited con. siderable interest. I should therefore desire to see the whole question more fully and candidly dealt with than it has been yet in the medical press. I should say that a medical periodical is the proper quarter to discuss it. Should circumstances allow me, I hope to make, at not too remote a period, such a reply to the "report" as to show that in place of the Belfast Royal Hospital being in a proper sanitary condition, and well suited to the safe and successful performance of capital operations within it walls, this institution has been, and still is, in a foul, impure, and objectionable condition for the reception of medical and surgical patients. The staff of the hospital have been coerced into this controversy ; their position and relationship to this institution and to its board of management are such that they cannot afford to dispute their arbitrary authority, as their existence or non-existence as members of the staff absolutely depends upon the favour or the frown of the former. More of this, I hope, hereafter. I am, Sirs, yours faithfully,

Oct. 31st, 1891

R. T. DILL.

** We fear, with the existing pressure on our space, we cannot open our columns to what would no doubt prove a prolonged discussion, whilst the issues involved are mainly of local interest.-ED. $\mathrm{L}$.

\section{THE OPERATION OF COMBINED PYLOREC- TOMY AND GASTRO-ENTEROSTOMY. To the Editors of THE LANCEr.}

Sins,--He is a daring man who, in these days, can confidently affirm-" The case I am now reporting is the first in which the operation has been performed in this country." This is what Mr. Bowreman Jessett says of his excellent case of combined pylorectomy and gastro-enterostomy, published in THE LANCET of Oct. 24th; and he has fallen into error, for an operation on exactly the same lines was performed by me in the Bristol Royal Infirmary on March 25th, 1891. Some of us may think that the terms "first," "first published," "first successful," "first successful published," and so forth, might be applied to operations with more propriety by others rather than by the operator himself. If "first" has to be applied to my operation, there can be no harm in speaking of it as the "first unsuccessful" case, and in saying that an account of it, or as much of it as is worth recording, has been in print for five months, and will be published soon. I may add that I wrote to Mr. Jessett and told him of my case, for I believed that he would like to correct his error in the current number of THE LANCET. As he has not done so, I venture to do it for him.

I am, Sirs, yours faithfully,

Clifton, Bristol, Nor. 2nd, $1891 . \quad$ J. GREIG SMITH.

\section{To the Editors of THE LANCET.}

SIRS, - In your issue of Oct. 24th, Mr. Jessett publishes a case in which he had performed the operation of combined pylorectomy and gastro-enterostomy with success on a patient suffering from pyloric cancer-a result which is most satisfactory. This operation was performed on Aug. 4th, 1891 , and in his paper (p. 923, line 22) he says: "The case I am now reporting is the first in which the operation has been performed in this country." This is searcely correct. On July 9 th. 1890, I saw a case of pyloric cancer in consultation, which I thought a very suitable one for removal. Dr. Lowson was chosen as the surgeon, and on July 25th, 1890 be performed the operation of combined pylorectomy and gastro-enterostomy. The case, which was not successful, has not been so far reported, but the merit of being the first to perform the operation in this country belongs rather to Dr. Lowson than to Mr. Jessett.

I am, Sirs, yours obediently,

Hull, Oct. 31st, 1891.

FraNk NicholsoN

\section{REMOVAL OF A FRAGMENT OF STEEL FROM} THE RETINA BY MEANS OF THE ELECTRO-MAGNET.

To the Editors of THE LANCET.

SIRS, - I have read with much interest the case reported in ThE LANCET of Oct. 24th by J. Tatham Thompson, M.B., under the above heading. In the last paragraph of 
the report it is stated, "So far as can be ascertained, the only cases previously reported of successful removal from the retina are those of Galezowski and Hirschberg." Allow me to inform Dr. Thompson that the case he has reported is similar to a case shown by me before operation to the Glasgow Patholoyical and Clinical Society in December last, and reported in the Glasgow Medical Journal for April, 1891. In this case, the right eye was struck with a chip of steel, which flew off the head of a hammer. The patient attended an eye hospital in England, and was treated for the small wound in the eye, but no foreign body was discovered. His sight gradually got worse, and he had pain in the eye, especially when at work. He came under my care at the Glasgow Eye Infirmary in November last, and on examination with the ophthalmoscope I discovered a dark body in the retina below the optic nerve, and presumably the chip of steel. I removed the chip of steel successfully by the electro-magnet through an opening made in the lower and outer quadrant of the eye. The patient and the small chip of steel extracted from the eye were shown to the Glasgow Pathological and Clinical Society in Jaruary, and the operation reported in the Glasgow Medical Journal for June, 1891. I am, Sirs, yours obediently,

Glasgow, Oct. 27th, 1891 T. SPENCE MEIGHAN, M.D.

\section{LIVERPOOL.}

\section{(From oUn OWN CoRrespondent.)}

Compensation for the Demolition of Insanitary Property.

A VERY important question has recently been raised here, and has, it is hoped, been satisfactorily settled. Some recent proceedings were taken by the Corporation for the demolition of property which had been declared by the medical officer of health and the grand jury to be insanitary. The amount of compensation offered to the owners by an arbitrator appointed by the Local Government Board was, in two or three instances, considered insufficient. An appea was therefore made by the owners, first to the Divisional Court, and subsequently to the Court of Appeal. The latter court held that the arbitrator should give some consideration to the rental value of the property, notwithstanding that the property was unfit for human habitation. The matter was subsequently referred back to the arbitrator, who has now issued a new award, the financial consequence of which is to increase the amount offered by the corporation to a sum midway between the amount originally offered and the amount claimed by the owners of the property. It is believed that this award will be satisfactory to the parties concerned.

Arrival at Gaol of a Dead Prisoner.

On Oct. 28th the city coroner held an inquest at H.M. Prison, Walton, on the body of a man who had been conveyed to the prison on Oct. $26 \mathrm{tb}$, and who died just as he was carried past the entrance-gate. Mr. Beamish, the principal medical officer of the prison, saw him immediately and found life extinct. A post-mortem examination was made by Mr. Lowndes, surgeon to the Liverpool police, in the presence of Mr. Beamish, about forty hours after death. Externally were two abrasions on the knees and some post-mortem stains on the thighs and legs. The right lung was almost entirely destroyed by disease, and the left indicated recent pneumonia. The heart contained an abnormal quantity of fat, and its walls were thickened. The liver showed commencing cirrhosis. The stomach contained a considerable quantity of food in an advanced state of digestion. The deceased was found begging in the streets of Birkenhead, and was taken to the Bridewell there, where he was detained till he could be brought before the magistrates. He had no cough, made no complaint of any illness, or any request to see a doctor. On Oct. 26 th he was brought before the magistrates and committed to gaol for fourteen days. He was brought by a constable across the river by the steamer to Liverpool, where he appeared somewhat faint, but soon revived. A delay of forty minutes occurred before the train started, during which he was apparently quite well. In the train he was permitted to smoke, and did so with evident enjoyment. From the Walton station to the gaol is a short walk, and during this the prisoner suddenly fell to the ground on his knees. He was raised and carried into the prison, where he evidently breathed his last as he entered. This case shows the importance of every prisoner being carefully examined by a medical practitioner before being sent to prison. The jury made a presentment to the effect that provision should be made for the detention of prisoners at Birkenhead for a limited time rather than that they should be removed, handcuffed, to such a distance.

\section{Hospital Sunday and Saturday.}

At the annual meeting of those interested in the Hospital Sunday Fund, held on the 2nd inst., the mayor presiding, the report of the committee was read by the Rev. T. B. Banner, one of the honorary secretaries. The first paragraph, which lent considerable interest to the proceedings, was as follows: "On the 2nd Nov, 1870, a meeting was held at the Town Hall, at which it was determined 'That it is desirable to have collections made in all places of worship on one day on behalf of the medical institutions of the town, this day to be called the Hospital Sunday.' The day of the annual meeting this year is exactly the twentyfirst anniversary of this inanguration, and it may possibly be interesting (the movement having now grown, as it were, from infancy to manhood) to recall one or two matters connected with its progress." The report proceeds to notice the choice of the second Sunday in the year, which, through evil and good report, has been maintained. The institution of Hospital Saturday, and its management by a separate body with most gratifying results, is next alluded to, as is also the principle on which the funds are distributed to the various medical charities. The Sunday collections this year were $£ 6973 \mathrm{l}$ 15s. $3 d$. (against $£ 6949$ last year), which, with bank interest ( $£ 64 \quad 11 s$ ) and donations $(£ 72 \quad 14 s \quad 6 d)$, made the total $£ 7111$ 0s. 9d. The Hospital Saturday collection amounted, with interest, to $£ 38508 s .6 d$, making the total fund $£ 10,83612 s$, out of which $£ 10,800$ was appropriated to the different medical charities. The whole expenses were comprised under the very moderate sum of $£ 12417 \mathrm{~s}$. $3 d$. for the Sunday collections, or 1.774 per cent., and $£ 39416 \mathrm{~s} .2 d$. for the Saturday Fund, or $9 \cdot 283$ per cent. Nov. 3rd.

\section{MANCHESTER.}

(FROM OUR OWN CORRESPONDENT.)

\section{Salford Royal Hospital.}

A DEFICIT of more than $£ 1200$ is the worst feature of the annual report of this institution. This deficit has been going on at the same rate for the past four years, and the committee point out that this cannot go on longer ; either more funds must be obtained, or some of the wards will have to be closed. This latter alternative it is to be hoped will be averted. It is not long since the hospital was enlarged to 120 beds through the munificence of a townsman at a cost of nearly $£ 30,000$, but the difficulty is to increase the permanent annual subseriptions. To maintain these, seeing how much the income of our hospitals now depends upon the contributions of the masses of the people, it has been urged that a more democratic governing body would perhaps infuse a more widespread interest in our medical charities. Eighteen thousand persons received medical relief during last year, and, being the only hospital in Salford, strenuous efforts on the part of the management must be made unless this work is to be greatly curtailed. As a result of the appeal made at the annual meeting, a gentleman of Gateshead-on-Tyne (formerly of Salford) has sent the treasurer $£ 100$. It is not that people in Manchester cannot contribute, for our recent $e$ ffort to raise money for the lifeboat funds has resulted in obtaining more than $£ 5300$, and for the relief of the Jews in Russia $£ 2000$ has been lately collected.

\section{Royal Infirmary Extension.}

In spite of protests made by a large and influential number of subseribers, the Board of Management of the Infirmary appear determined to proceed as far as they can with the extension scheme, and in a few weeks complete plans with full details will be ready for submitting to the governors, who have, however, not yet been permitted to offer any opinion as to the policy of such extension. Judging from the fact that a large section of the public, thecorporation, and many subscribers as well as members of the medical staff are strong opponents to the project, it is most probable that some compromise will have to be come to with $O$ wen's 